\title{
The impact of pore pressure boundary conditions in stope backfilling models
}

\author{
JP Doherty The University of Western Australia, Australia
}

\begin{abstract}
Fully coupled numerical models for simulating mine backfill typically assume zero pore pressure conditions at the top of the fill. This implies full saturation of the fill mass. In this paper, Gibson's solution is examined to identify situations where this use of zero pore pressure boundary conditions is likely to be unrealistic. A model that is able to capture phreatic draw down and fill desaturation is then briefly described. The model also accounts for changes in strength, stiffness and permeability due to cement hydration. An example two-dimensional simulation of stope backfilling is then presented. The analysis is conducted assuming full saturation and zero pore pressure boundary conditions, as well as a more realistic simulation that accounts for desaturation. It is shown that phreatic draw down and fill desaturation have a significant impact on pore pressure within the fill mass and barricade loads.
\end{abstract}

\section{$1 \quad$ Introduction}

Barricades are usually constructed in access drives at the base of mine stopes to contain the backfill during filling operations, as it consolidates (under self-weight loading) from its initial slurry-like state (Figure 1). Filling must be carefully carried out to ensure the barricade design loads are not exceeded, as barricade failures not only pose a serious risk to the safety of mine site personnel, but there are also significant economic consequences as a result of mine down time during the clean-up.

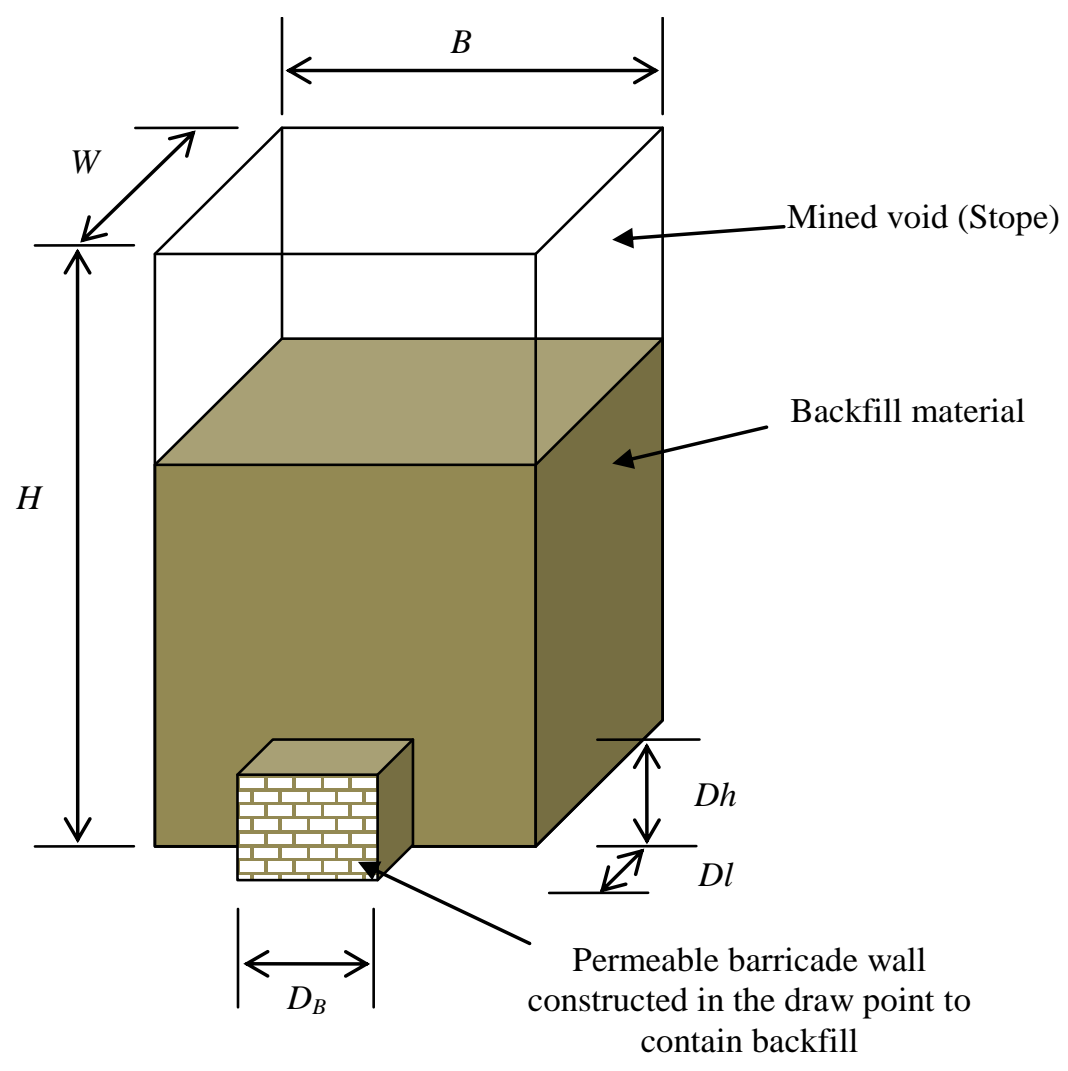

Figure 1 Typical stope geometry 
The development of rational fill management strategies requires ability to forecast barricade loads during and after filling. This, in turn, requires a sound understanding of the mechanics of mine backfill. Research projects are currently underway at the University of Toronto (e.g. Thompson et al. 2011) and the University of Western Australia (e.g. Helinski et al. 2011; Hasan et al. 2013) to collect in-stope measurements of pore pressure, total stress and temperature. An ability to back-analyse these stopes with realistic numerical models is essential for meaningful interpretation and ultimately the development of tools to facilitate backfill management.

This paper uses a fully coupled multi-physics finite element model developed by Doherty (2013a) to study the stress state both during and after stope filling for partially consolidating backfill. The analysis is coupled in the sense that the material constitutive model and the equilibrium equations are combined with Biot's (Biot 1941) time-dependent consolidation. Other coupled models, for example special purpose program developed by Helinski (2008) and those employing FLAC (i.e. Li \& Aubertin 2009), prescribe zero pore pressure boundary conditions to the upper fill surface. These models are therefore unable to simulate phreatic draw down and subsequent desaturation and are therefore not suited to simulating free draining mine fill situations in which the phreatic surface falls below the fill surface during filling. The model by Doherty (2013a) is able to model the entire range of fill behaviour. However, the focus of this paper is restricted to free draining mine stopes, where phreatic draw down and desaturation are important mechanisms in determining barricade loads.

In the following section of the paper, Gibson's chart (Gibson 1958) is presented and used to classify backfilling as free draining when the phreatic surface falls below the fill height during filling. Following this, a brief summary on the finite element model is presented along with an example two-dimensional application of the model to demonstrate the importance of appropriately modelling the pore fluid boundary conditions.

\section{$2 \quad$ Fill classification and pore fluid boundary conditions}

To classify a stope as either 'non-consolidating' or 'fully-consolidating', Fahey et al. (2010) applied Gibson's solution (Gibson 1958) for the self-weight consolidation of a sediment increasing in thickness $(H(t))$ with time $(t)$, at a constant rate $(m)$ (i.e. $H(t)=m t$ ). Gibson's solutions are developed in terms of excess pore pressure $u$ and assume a constant permeability $k$, a constant constrained modulus $E_{0}$ and therefore a constant coefficient of consolation $c_{v}$.

$$
c_{v}=\frac{E_{0} k}{\gamma_{w}}
$$

Where $\gamma_{w}$ is the unit weight of water. The particular case considered relevant to mine backfill (Fahey et al. 2010) assumes a drained base (i.e. $u=0$ at $z=0$ ). Numerical solutions to this problem can be expressed in terms of a dimensionless time factor $T$, where:

$$
T=\frac{m^{2} t}{c_{v}}
$$

Figure 2 plots isochrones of excess pore pressure normalised by the overburden stress $(u / \gamma H)$ against normalised height $(z / H)$ for a range of dimensionless time factors $(T)$. Fahey et al. (2010) identified a number of limitations in the application of Gibson's solution to mine backfill, but suggest it is a useful screening tool for determining the consolidation characteristic of a stope. For example, Helinski et al. (2011) suggest that for $T>100$ filling is almost completely undrained (non-consolidating) and for $T<1$, filling is close to fully drained (consolidating). One further limitation of Gibson's solution, that appears not to have been previously recognised, is that Gibson's solution is formulated in terms of self-weight induced excess pore pressures, not total pressure. Therefore, low $T$ values result in pore pressures approaching zero (see Figure 2). In reality, very slow filling rates would result in the phreatic surface falling below the fill surface during filling. This would lead to negative (suction) pore pressures above the phreatic surface. To demonstrate this, self-weight consolidation was modelled numerically using the Abaqus finite element 
software package, by creating a one-dimensional model composed of separate layers. Initially all layers were deactivated. A staged analysis was then conducted by activating layers from the bottom up at a rate corresponding to a given fill rate. Self-weight loading was applied to each layer, with zero pore pressure boundary conditions prescribed to the bottom of the model and to the top of the active upper layer. Results from the Abaqus analysis are also shown in Figure 2 and demonstrate an excellent match to Gibson's solution. This validates the numerical approach for simulating self-weight consolidation in a backfilling situation.

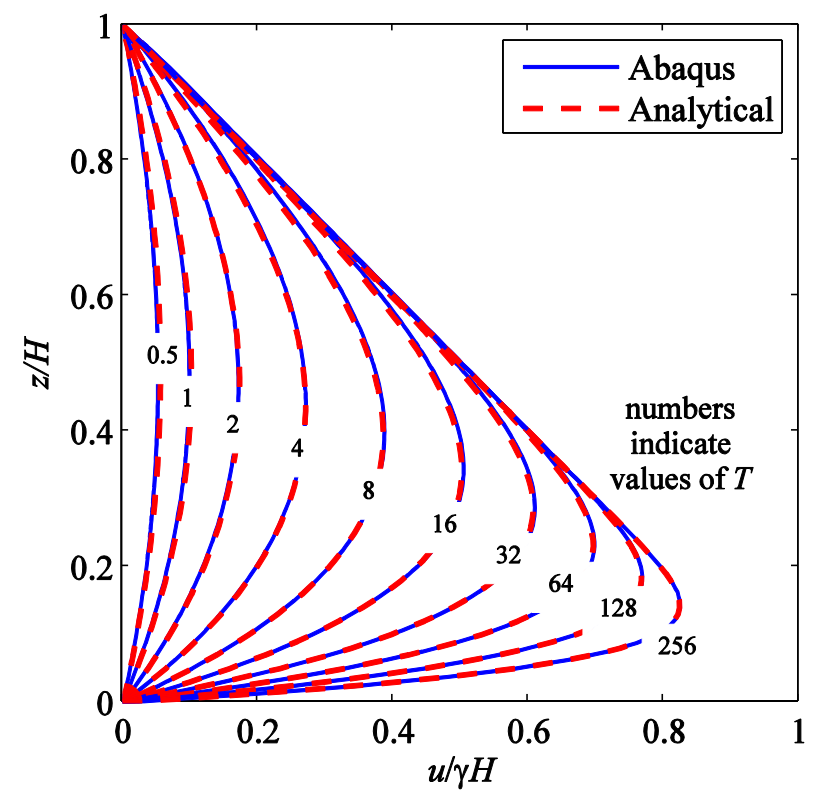

Figure 2 Comparing isochrones of pore pressure from Gibson's solution and finite element analysis

Figure 3 plots the normalised pore fluid flux at the upper boundary as a function of $T$ (where $Q$ is the volume flux, $A$ is the cross-sectional area of the one-dimensional model and $k$ is the permeability of the material). As indicated in the figure, a positive volume flux indicates water from within the column flows up and out of the model, whereas additional pore fluid must enter the model for negative volume flux. Figure 3 shows the transition from pore fluid leaving the model to entering the model occurs between $T$ of 1 and 2. In a mine backfill situation, there is no actual source for any additional pore fluid to enter the model when $Q<0$. In this situation, prescribing zero pore pressure boundary conditions is likely to be highly unrealistic. This in effect simulates the addition of extra water not actually present in the real problem. To overcome this, the model employed in this paper uses drainage-only (DO) boundary conditions instead of zero pore pressure boundary conditions (such as those used by Helinski 2008; Li \& Aubertin 2009). These boundary conditions imply that normal pore fluid flow occurs only from the interior to the exterior region of the model in proportion to the magnitude of the current pore pressure on the boundary when that pressure is positive (i.e. compressive). When surface pore pressures are negative (suctions), the constraint enforces the condition that no fluid can enter the interior region. However, the model does allow air to enter and desaturate the fill by specifying a soil water retention curve that relates saturation level to negative pore pressure.

The following section of the paper presents a simple two-dimensional example analysis that demonstrates the difference between zero pore pressure boundary conditions and drainage only boundary conditions. 


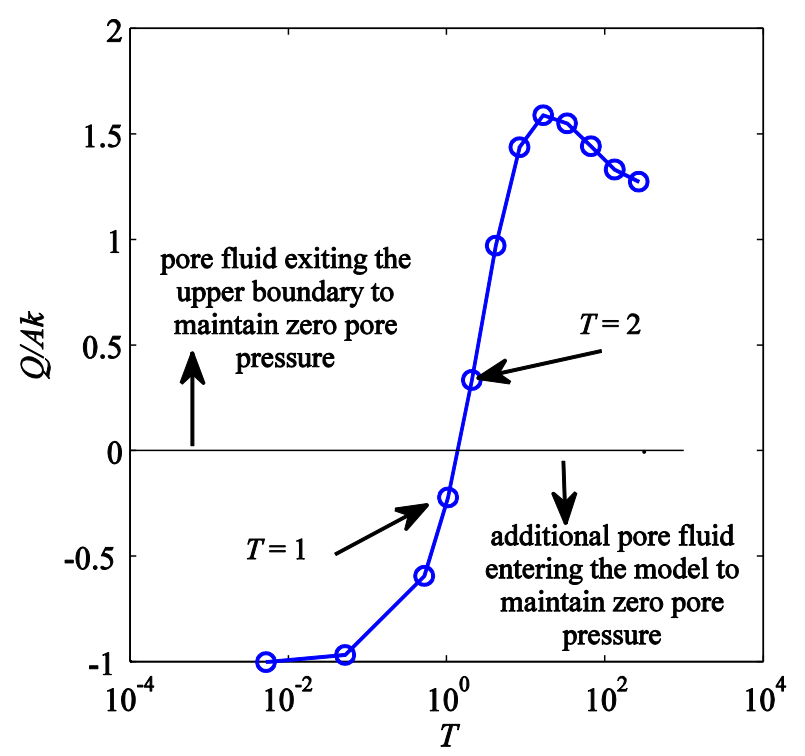

Figure 3 Normalised pore fluid flux at upper surface of one-dimensional model

\section{Example 2D application}

\subsection{Constitutive model assumptions}

The constitutive model was elastic perfectly plastic and used the Mohr-Coulomb yield condition, which is defined in terms of a friction angle $(\phi)$, a dilation angle $(\psi)$ and cohesion $\left(c\left(t^{\prime}\right)\right)$. The model makes the simplistic assumption that friction and dilation remain constant over time, while the cohesive component of strength increases with hydration time $\left(t^{\prime}\right)$. The following expression was used to represent the increase in cohesive strength as backfill hydrates:

$$
c\left(t^{\prime}\right)=c_{i}\left(\lambda_{c}-\left(\lambda_{c}-1\right) \exp \left(-\kappa_{h} t^{\prime}\right)\right)
$$

Where $c_{i}$ is the initial cohesion, $\kappa_{h}$ is a model parameter representing the rate of hydration and $\lambda_{c}$ is the ratio of the final cemented strength to the initial cemented strength. The initial cohesion prior to any cementation is zero. However, a zero cohesion value can cause numerical difficulty. Therefore, in this model, $c_{i}$ was taken to be $1 \mathrm{kPa}$ (small non-zero value), therefore $\lambda_{c}$ is the final cemented strength after full hydration. The bulk stiffness $\left(K_{s}(t)\right)$ was also assumed to increase with hydration time using a similar expression.

$$
K_{s}\left(t^{\prime}\right)=K_{s i}\left(\lambda_{k s}-\left(\lambda_{k s}-1\right) \exp \left(-\kappa_{h} t^{\prime}\right)\right)
$$

Where $K_{s \mathrm{~s}}$ is the initial bulk stiffness and $\lambda_{\mathrm{ks}}$ is the ratio of the final bulk stiffness to the initial bulk stiffness. It has also been observed that the permeability of mine backfill reduces over time due to cement hydration. To account for the reduction in permeability $\left(k\left(t^{\prime}\right)\right)$ over time, the following function was used:

$$
k\left(t^{\prime}\right)=k_{i}\left(\lambda_{k}-\left(\lambda_{k}-1\right) \exp \left(-\kappa_{h} t^{\prime}\right)\right)
$$

Where $k_{\mathrm{i}}$ is the initial permeability and $\lambda_{\mathrm{k}}$ is the ratio of the final permeability to the initial permeability (taking a value less than unity to represent a reduction). The complete list of model parameters used in the analysis is given in Table 1. Note, a distinction between fill time $t$ (i.e. the time elapsed since commencing stope filling) and hydration time $t$ ' is necessary because the hydration time varies at any instant throughout the model. For example, material at the base of the stope is older than material at the top and will therefore have a lager hydration time. In the model, $t^{\prime}$ for a particular point begins $t_{0}$ after the point is activated in the fill sequence, where $t_{0}$ is a model parameter known as the time to hydration. 
Table 1 Material parameters

\begin{tabular}{cc}
\hline Material property (units) & Value \\
\hline Cohesion $c\left(t^{\prime}\right)(\mathrm{kPa})$ & $c_{i}=1 \mathrm{kPa}, \lambda_{c}=80(-)$ and $\kappa_{h}=8.3 \times 10^{-3} \mathrm{hrs}^{-1}$ \\
Friction angle $\phi$ (degrees) & 0 \\
Dilation angle $\psi$ (degrees) & $K_{s i}=24 \mathrm{MPa}, \lambda_{K s}=23(-)$ and $\kappa_{h}=8.3 \times 10^{-3} \mathrm{hrs}^{-1}$ \\
Bulk soil stiffness $K_{s}\left(t^{\prime}\right)(\mathrm{MPa})$ & 0.2 \\
Poisson's ratio $\mu(-)$ & 16.0 \\
Dry Unit Weight $\gamma\left(\mathrm{kN} / \mathrm{m}^{3}\right)$ & 9.81 \\
Unit weight of water $\gamma_{w}\left(\mathrm{kN} / \mathrm{m}^{3}\right)$ & 0.42 \\
Porosity $n(-)$ & Where $k_{i}=4 \times 10^{-8}(\mathrm{~m} / \mathrm{s}), \lambda_{k}=0.33(-)$ and $\kappa_{h}=8.3 \times 10^{-3} \mathrm{hrs}^{-1}$ \\
Permeability $k\left(t^{\prime}\right)(\mathrm{m} / \mathrm{s})$ & 7.2 \\
Time to hydration $t_{0}(\mathrm{hrs})$ &
\end{tabular}

\subsection{Geometry and boundary conditions}

The geometry of mine stopes vary significantly from mine to mine (and within a given mine). The majority of mine stope geometries would be best represented using a full three-dimensional model. While the model described in this paper can be applied to full three-dimensional problems, the focus here is on the influence of pore pressure boundary conditions. As such, two-dimensional plane strain analysis is considered adequate. The draw point length and height were taken as $6 \mathrm{~m}$, the total height of the stopes ( $H$ in Figure 1 ) was $40 \mathrm{~m}$ and for width $W=20 \mathrm{~m}$. Because the draw point is typically narrower than the stope (see Figure 1), the permeability in the draw point was reduced by a factor of three to represent the hydraulic choke caused by the geometric constriction that is absent in the plane strain model. This technique has also been employed by Helinski et al. (2011).

To simulate backfilling, the two-dimensional (plane strain) stope model was created in $1 \mathrm{~m}$ high layers. Initially all layers were deactivated to represent an empty stope. Layers were then activated from the bottom up, with drainage boundary conditions applied to the top of the new layer (Figure 4) and deactivated from the previous top. Gravitational acceleration was applied to each new layer over a time period corresponding to the fill rate. This was taken as $0.3 \mathrm{~m}$ per hour vertical rate of rise for the first $10 \mathrm{~m}$ of filling. This was followed by a $24 \mathrm{hr}$ rest period before filling the remainder of the stope to a total of $40 \mathrm{~m}$ high at a rate of $0.24 \mathrm{~m}$ per hour. The total time to fill the stope was $184 \mathrm{hrs}$. All boundary nodes were fully fixed (i.e. displacements are prevented in both the vertical and horizontal direction). Therefore a major assumption is that there is no slip between the backfill material and the surrounding rock mass. This is a common assumption in mine backfill modelling given the typical roughness of the rock walls (e.g. Helinski et al. 2011).

The application of appropriate drainage boundary conditions is discussed in detail by Doherty (2013b) and further discussed above with reference to Gibson's solution. For all simulations in this paper, drainage with air entry boundary conditions were applied to the barricade wall and the upper fill surface. That is, normal pore fluid flow could occur only from the interior to the exterior region of the model in proportion to the magnitude of the current pore pressure on the boundary when that pressure is positive (i.e. compressive). When surface pore pressures are negative, the constraint enforced the condition that no fluid can enter the interior region. This boundary condition is considered realistic for describing the pore pressure boundary conditions at the barricade wall in the sense that once pore fluid flows out of the wall it does not pool and can therefore not flow back into the stope. The same boundary condition prescribed on the upper surface of the stope is also considered reasonable. However, it should be noted that the pore pressure on the top 
fill surface can never be greater than zero. Therefore, the model cannot simulate ponding of water on the fill surface, or re-entry of this ponded water into the stope. When the pore pressures are negative, the model allows air to enter the stope (at the upper fill surface and at the barricade wall) and desaturate the fill mass in accordance with a specified soil water characteristic curve. The soil water characteristic curve (along with increased and decreased curves used later in the parametric study) is presented in Figure 5 . The base case soil water characteristic curve was derived from Fredlund and Xing (1994) for silty sand.

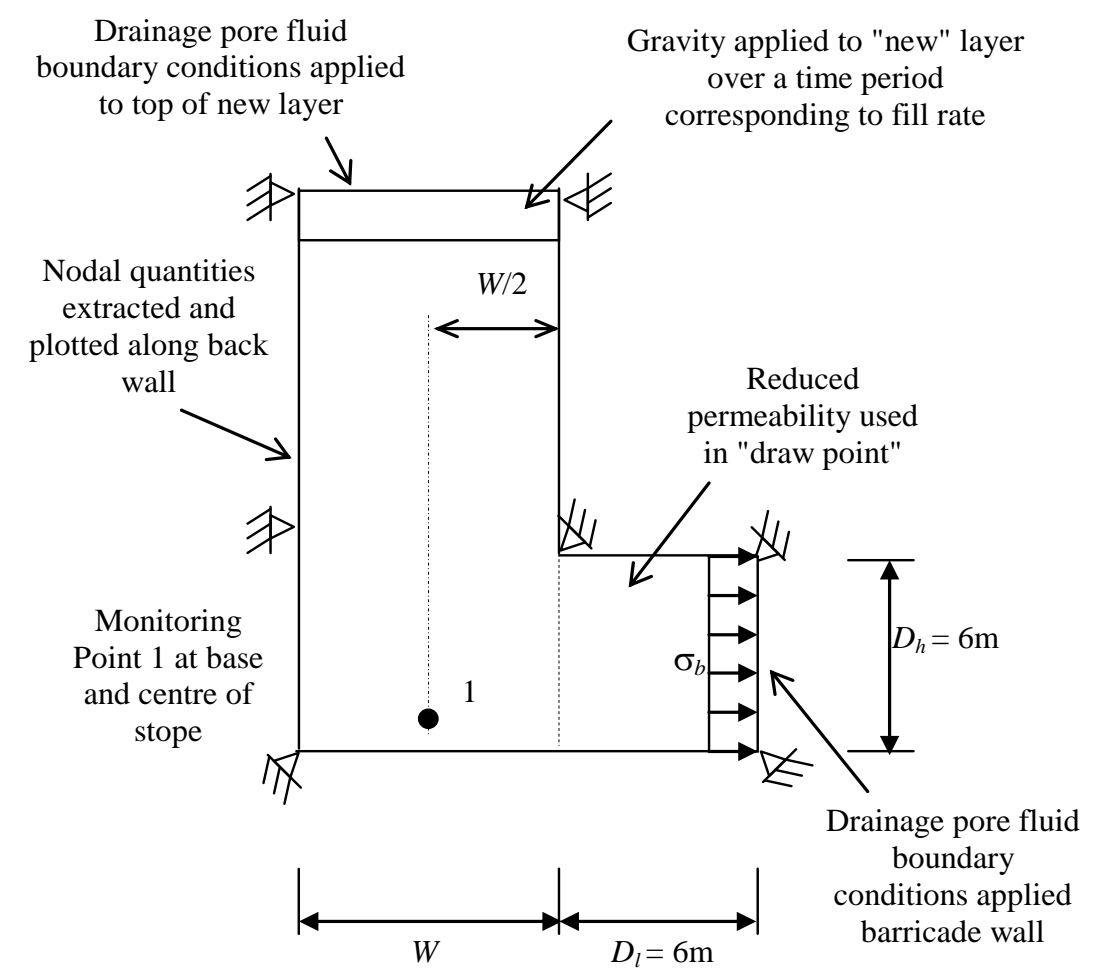

Figure 4 Boundary conditions for two-dimensional stope filling model

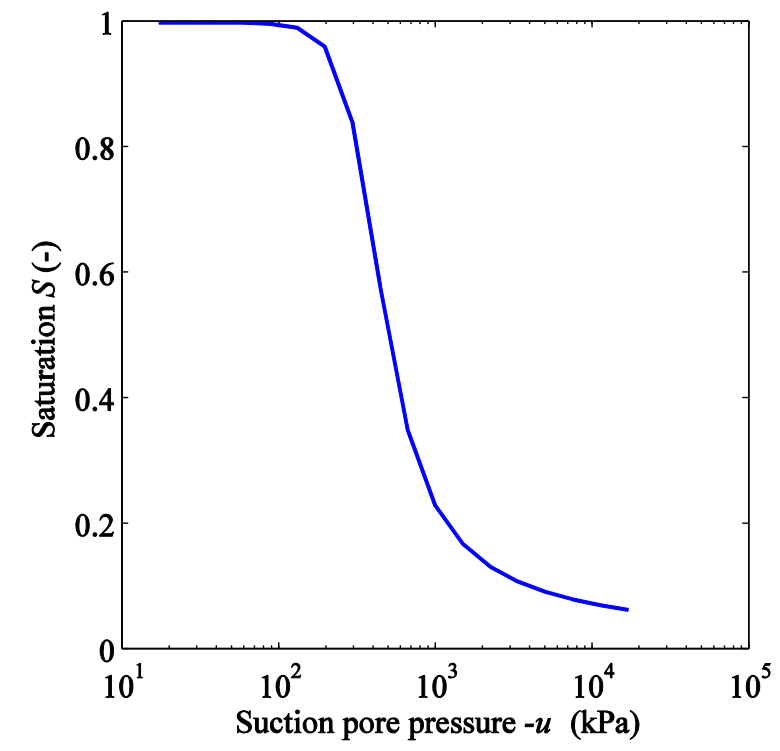

Figure 5 Soil water retention curve

\subsection{Results}

As both bulk stiffness and the permeability vary throughout filling due to hydration, the coefficient of consolidation varies from $70 \mathrm{~m}^{2} / \mathrm{hr}$, at the start of hydration, to around $600 \mathrm{~m}^{2} / \mathrm{hr}$, after full hydration. 
These values also vary through the depth of the stope, as fill at the base has experienced more hydration time than fill above. At fill completion, $H=40 \mathrm{~m}$ and the total fill time is $t=184 \mathrm{hrs}$. Using the average fill rate, i.e. $m=40 / 184=0.22 \mathrm{~m} / \mathrm{hr}$, Gibson's time factor ranges between 0.1 (for $c_{v}=70 \mathrm{~m}^{2} / \mathrm{hr}$ ) and 0.015 (for $c_{v}=600 \mathrm{~m}^{2} / \mathrm{hr}$ ) through the depth of the model. For either of these values, a significant fall in the phreatic surface is expected during filling based on Figure 3.

Figure 6 plots the average barricade stress $\left(\sigma_{b}\right)$ and the pore pressure at monitoring Point 1, i.e. illustrated in Figure 4, against time. The average barricade stress was calculated by summing the nodal reaction forces at the barricade wall and dividing by the height of the wall. Figure 6 also shows results from the same model, but run using zero pore pressure boundary conditions. It can be seen that the barricade stress is almost double when zero pore pressure boundary conditions are assumed. The reason for this is illustrated in Figure 7, which shows the phreatic surface (interpreted as the elevation with zero pore pressure) drops $13 \mathrm{~m}$ below the fill surface for the drainage model, but remains at the fill surface for the zero pore pressure model. The fall in the phreatic surface is consistent with expectations based on examination of the direction of pore fluid flow in Figure 3.

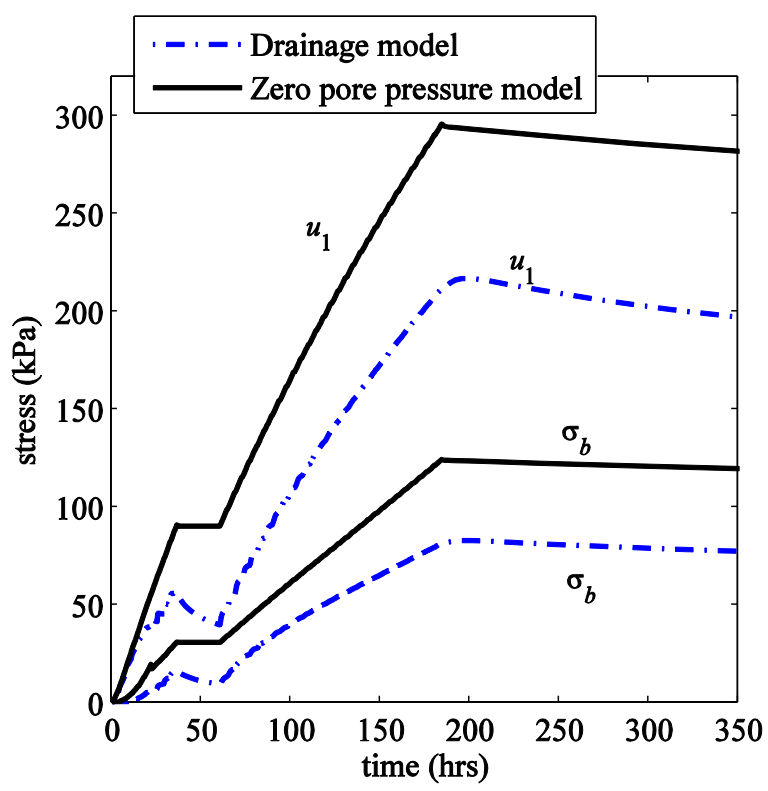

Figure 6 Pore pressure at monitor Point 1 and average barricade stress versus time 


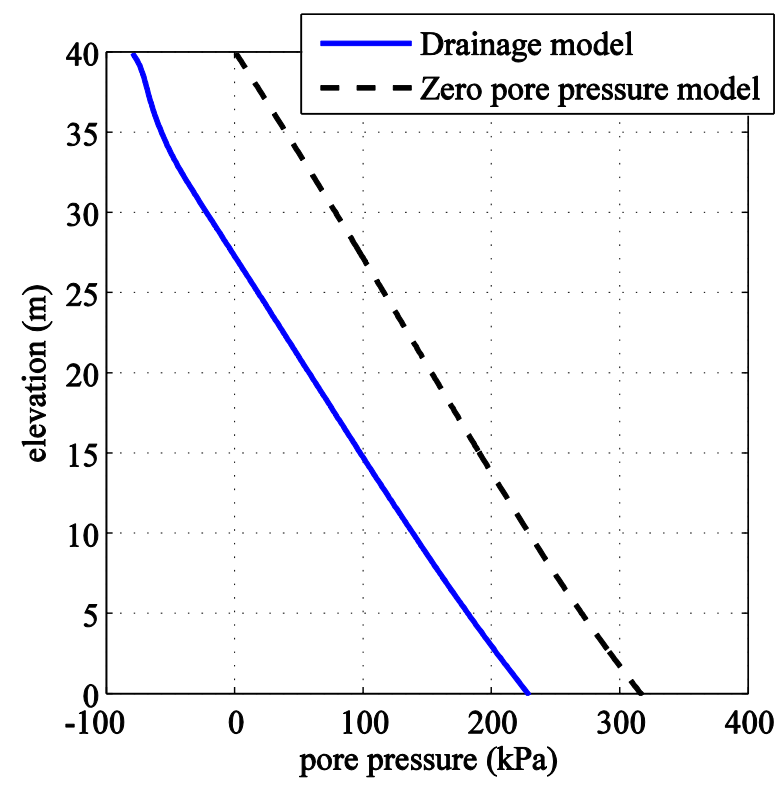

Figure 7 Pore pressure profile along back wall of stope at completion of filling

\section{$4 \quad$ Conclusions}

Models for simulating the filling of mine stopes are important for developing an understanding of the factors that impact barricade loads during and after filling. This paper examines Gibson's solution to identify the backfill situation where the phreatic surface is likely to fall below the fill surface during filling. Two simulations are then presented to compare the results from a model that adopted zero pore pressure boundary conditions (and therefore full saturation) with a model that captures phreatic draw down and fill desaturation. It is shown that phreatic draw down and fill desaturation have a significant impact on pore pressure within the fill mass and barricade loads.

\section{Acknowledgement}

This work was carried out as part of an Australian Research Council linkage project 'Behaviour of Cementing Backfill in Full Scale Mining Stopes' (LP100200173). The author would like to thank project sponsors Barrick Gold of Australia Ltd and Panoramic Resources Ltd.

\section{References}

Biot, MA 1941, 'General theory of three-dimensional consolidation', Journal of Applied Physics, vol. 12, pp. 155-164.

Doherty, JP 2013a, 'A model for cemented backfill incorporating chemical volume strains: I. Development of a constitutive model', Canadian Geotechnical Journal, in review.

Doherty, JP 2013b, 'A model for cemented backfills incorporating chemical volume strains: II. Application', submitted to Canadian Geotechnical Journal.

Fahey, M, Helinski, M \& Fourie, AB 2010, 'Consolidation in accreting sediments: Gibson's solution applied to backfilling of mine stopes', Géotechnique, vol. 60, no. 11, pp. 877-82.

Fredlund, D \& Xing, A 1994, 'Equations for the soil-water characteristic curve', Canadian Geotechnical Journal, vol. 31, no. 6, pp. 521-32.

Gibson, RE 1958, 'The progress of consolidation of a clay layer increasing in thickness with time', Géotechnique, vol. 8, no. 4, pp. 171-82.

Hasan, A, Suazo, G \& Fourie, AB 2013, 'Full scale experiments on the effectiveness of a drainage system for cemented paste backfill', RJ Jewell, AB Fourie, J Caldwell \& J Pimenta (eds), Proceedings of the 16th International Seminar on Paste and Thickened Tailings, Australian Centre for Geomechanics, Perth, pp. 379-92.

Helinski, M 2008, 'The mechanics of mine backfill', PhD thesis, The University of Western Australia.

Helinski, M, Fahey, M \& Fourie, AB 2011, 'Behavior of cemented paste backfill in two mine stopes: Measurements and modeling', Journal of Geotechnical and Geoenvironmental Engineering, vol. 137, no. 2, pp. 171-82.

Li, L \& Aubertin, M 2009, 'Influence of water pressure on the stress state in stopes', Geotechnical and Geological Engineering, vol. 27 , no. 1, pp. 1-11. 
Thompson, BD, Bawden, WF \& Grabinsky, MW 2011, 'In situ measurements of cemented paste backfill at the Cayeli Mine', Canadian Geotechnical Journal, vol. 49, no. 7, pp. 755-72. 